\title{
MİKRONİZE ÖĞÜTMEDE HAVALI AYIRICILARIN TASARIM DEĞİŞKENLERİ
}

\author{
Öner Yusuf TORAMAN ${ }^{1, *}$ ve Ali Tolga SÖNMEZ ${ }^{2}$ \\ ${ }^{I}$ Maden Mühendisliği Bölümü, Mühendislik Fakültesi, Niğde Üniversitesi,51240, Niğde, Türkiye \\ ${ }^{2}$ Fen Bilimleri Enstitüsü, Niğde Üniversitesi 51240, Niğde, Türkiye
}

\begin{abstract}
ÖZET
Günümüzde mikronize öğütme tesisleri, yüksek hızlı dinamik havalı ayırıcıların (separatör) gelişmesi ve yaygın olarak kullanılmaya başlamasıyla birlikte özellikle kalsit, talk, barit gibi orta sertlikteki $(<$ mohs'3) endüstriyel hammaddelerin $\mathrm{d}_{97} 25 \mu \mathrm{m}\left(\mathrm{d}_{50} 5 \mu \mathrm{m}\right)$, hatta daha düşük tane boyutlarına kadar $\left(\mathrm{d}_{97} 6 \mu \mathrm{m}\right)$ bilyalı değirmenler vasıtasıyla verimli bir şekilde öğütülmesine imkan tanımaktadır. Bu ekipmanları diğer sınıflandırıcılardan ayıran başlıca özellikleri, bir ana santrifüj fan ile hızlandırılıp basıncı arttırılmış hava kullanmaları ve ürünü bir siklon ve/veya jet-filtre ile durdurmalarıdır. Sisteme fan ve filtre girdiğinden dolayı da tasarım parametreleri daha karmaşıktır. Bu çalışmada; havalı ayırıcılar ve tasarım parametreleri ele alınarak uygulamadan örnekler sunulacaktır.
\end{abstract}

Anahtar Kelimeler: Mikronize öğütme, havalı ayırıı, tasarım değişkenleri

\section{DESIGN PARAMETERS OF AIR SEPARATORS IN MICRONIZED GRINDING}

\begin{abstract}
Today, with the latest improvements at the high-speed dynamic air classifiers, it is possible to grind industrial minerals such as calcite, talc, barite etc. of medium hardness ( $<$ mohs' 3 ) down to $d_{97} 25$ microns $\left(\mathrm{d}_{50} 5\right.$ microns); even down to $d_{97} 6$ microns particle size, which can be considered as ultra fine range, by means of a conventional ball mill, effectively. The main difference of these classifiers from static separators is the usage of high pressurized air with a high velocity generated by a centrifugal fan and stopping the product with the help of an air cyclone and/or jet-filter. Since a high-pressure fan and a jet-filter are included in the system, the design parameters are more complicated. In this article, air separators and their design parameters will be discussed and given some examples of the typical applications.
\end{abstract}

Keywords: Micronized grinding, air separator, design parameters

\section{GíRiş}

Havalı sınıflandırma (ayırma), hava akışı ile taneleri boyutuna, şekline ve özgül ağırlığına göre ayırma işlemidir ve kuru olarak gerçekleştirilmektedir. Ayırma işlemi $\mathrm{d}_{50}$ boyutu ile karakterize edilmektedir. $\mathrm{D}_{50}$ 'nin üzerindeki taneler "iri” fraksiyonu, altındakiler ise "ince" fraksiyonu ifade eder. Ayırmanın performansı elde edilen üründeki her bir fraksiyonun kütle içerikleriyle belirlenir [1].

*Tel.:+90 (388) 2252290; fax: +90 (388) 2250112. e-mail: otoraman@nigde.edu.tr 
Günümüz mikronize (ince ve çok ince) öğütme tesisleri, yüksek hızlı dinamik havalı ayırıcıların (separatör) gelişmesi ve yaygın olarak kullanılmaya başlamasıyla birlikte özellikle kalsit, talk, barit gibi orta sertlikteki (<mohs'3) endüstriyel hammaddelerin $\mathrm{d}_{97} 25 \mu \mathrm{m}\left(\mathrm{d}_{50} 5 \mu \mathrm{m}\right)$, hatta daha düşük tane boyutlarına kadar $\left(\mathrm{d}_{97} 6 \mu \mathrm{m}\right)$ bilyalı değirmenler vasıtasıyla verimli bir şekilde öğütülmesine imkan tanımaktadır. Gelişen dinamik havalı ayırıcılarla, güvenilirlikleri, düşük bakım ve işletme maliyetleri ile yumuşak ve orta sert hammaddelerin kuru ince öğütme uygulamalarında $\mathrm{d}_{97} 6 \mu \mathrm{m}$ düzeyine kadar kullanılan bilyalı değirmenler, enerji verimlerinin nispeten düşük olmasına karşın, sektörde hala lider konumundadır.

İnce-kalın malzeme sınıflandırmasının ilk olarak eleklerle yapıldığı; en basit ve etkin havalı sınıflandırmanın ise binlerce yıldır harmanlarda dirgenlerle samanla karışık buğdayı havaya savurarak gerçekleştirildiği söylenebilir. Günümüz modern dinamik havalı ayırmanın esası ise temel prensip olarak aynıdır. Fan tarafından belirli hıza ulaştırılmış hava, bir rotorun merkezkaç kuvvetiyle aksi yönden gelen tanelerle karşılaşır; ince taneler merkezkaç kuvvetinin etkisiyle rotorun dışına taşınırken iri taneler dışarıdan fan tarafından hızlandırılmış havanın etkisiyle rotorun merkezinde kalarak ayrılırlar.

Bir mikronize öğütme tesisi tasarım aşamasında, öğütülmesi istenen hedef tane boyut aralığı için kullanılacak değirmenin çapı-boyu, boşaltım mekanizması, seçilecek ayırıcının cinsi, tipi, yataklama şekli, rotor çapı, ürünü durduracak durdurucu siklon ve/veya jet filtre ve en önemlisi ana fan uyumlu olmalıdır. Bu parametrelerden biri ya da birkaçı uyumsuzluk gösterdiğinde, hedeflenen tane boyutunun elde edilememesi, istenilen kapasitede ürün alınamaması, enerji verimliliğinin düşük olması gibi sonradan çözülmesi çok zor ve pahalı sorunlar ortaya çıkabilmektedir. Bazı durumlarda ise tesisin gerçek kapasitesinin bu olduğu varsayılarak uzun süre düşük verimde çalıştırılabilmektedir. Bu tür olumsuzlukları yaşamamak için hem tasarımcının, hem de işletmecinin adı geçen parametrelerle ilgili bilgi sahibi olması gerekmektedir.

\section{STATIKK HAVALI AYIRICILAR}

Statik havalı ayırıcılar, dar tane boyut dağılımına çok ihtiyaç duyulmayan, az da olsa iri tane kaçağının fazla önemsenmediği yaklaşık 20 yıl öncesine kadar kuru ögütme sistemlerinin en çok kullanılan sınıflandırıcısı konumundaydılar. Günümüzde özellikle $\mathrm{d}_{97} 45-250 \mu \mathrm{m}$ tane boyut aralığında ürün elde edilmesinde kullanılabilmelerine karşın, artık yerlerini fan-filtre destekli dinamik havalı ayırıcılara bırakmışlardır. Özellikle kalsit, talk, kaolin, barit vb. dolgu maddeleri üreten yeni mikronize öğütme tesislerinde neredeyse tümüyle ortadan kalkmıştır.

Değirmen çıkışı malzeme, ayırıcının içinde en üst kısmında bulunan dağıtım plakası üzerine beslenir. Burada merkezkaç kuvvetinin etkisiyle bir altta bulunan döner plakanın üzerine dökülen malzemenin iri taneleri merkezkaç kuvvetinin etkisiyle dış kısımda kalır ve yerçekimiyle aşağı dökülüp geri beslemeye verilir veya ayrılır. İnce olanlar ise dönen plakaların etkisiyle oluşan hava sirkülasyonuna kapılarak yukarı taşınır ve ince tane konisinde birikerek dışarı nihai ürün olarak alınır (Şekil 1).

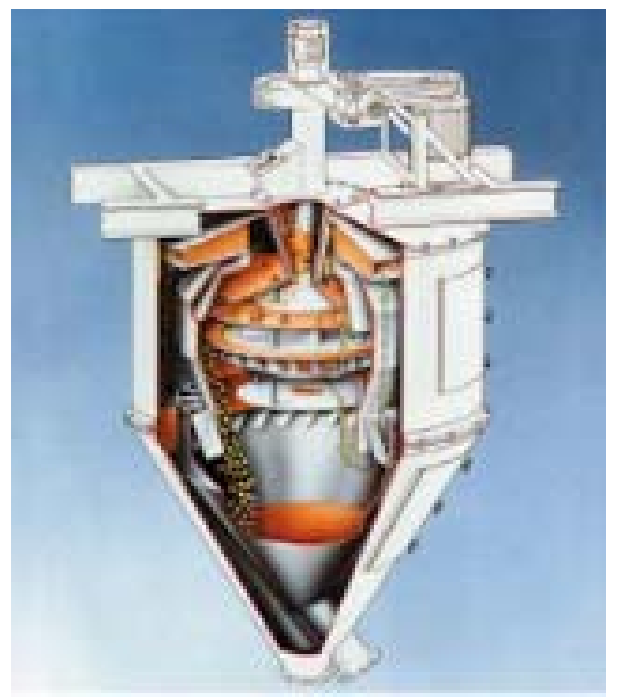

Şekil 1. Statik havalı ayırıcı kesit görünümü [2] 
Statik havalı sınıflandırıcıların başlıca avantajları şu şekilde sıralanabilir:

- Kurulumları ve yapıları basittir.

- Basit yapılarıyla dinamik ayırıcı sistemlerine kıyasla son derece düşük ilk yatırım maliyetleri vardır.

- İlave bir fan ve filtre sistemine ihtiyaç duymadıkları için toplam enerji tüketimi dinamik ayırıcılara nazaran oldukça düşüktür. (1/10-1/15 oranında)

- Basit yapılarından dolayı bakım ve işletme maliyetleri yok denecek kadar azdır.

- Tesis içinde montaj için gerekli yer ve yükseklik ihtiyacı azdır.

- Montajı ve sökülmesi kolay olduğundan tesis tasarımında ve operasyonda kolaylık sağlar.

- Tane boyut aralığı üretimi kesmeden değiş̧tirilebilir.

- Aşırı yüklenmelere karşı dayanıklıdır; bir başka deyişle herhangi bir sebepten ortaya çıkabilecek aşırı yükte tıkanma ve bozulma gibi bir sorunu yoktur.

Sayılan tüm avantajlara rağmen aşağıda belirtilen konulardaki yetersizlikleri, statik sınıflandırıcıların kullanımını ciddi ölçüde sınırlamaktadır:

- $\quad-45 \mu \mathrm{m}$ tane boyunun altında ayırma yapamamaktadır.

- Ayırdığı iri tanenin içine, değirmen geri beslemesine fazla miktarda ince kaçağı bırakmaktadır. Bu durum da prosesin genel enerji verimliliğini düşürmekte, aşırı öğütülmüş tane miktarını artırmaktadır.

- Sinıflandırmada tane boyut dağılım eğrisi dik değildir. Ürün tane boyutu, geniş bir aralıkta dağılım gösterir.

- En önemlisi de ayırdığı üründe az da olsa iri tane kaçağı bulunmaktadır.

Ancak yukarıda sayılan dezavantajların fazla önemli olmadığı, örneğin liç öncesi kuru öğütme gibi uygulamalarda hala statik havalı sinıflandırıcilar kullanım alanı bulmaktadır.

\section{DİNAMIKK HAVALI AYIRICILAR}

Dinamik havalı ayırıcılar son 30 yıl içinde kuru öğütme sistemlerinde en çok tercih edilen sinıflandırıcılardır. Bu ekipmanları diğer sınıflandırıcılardan ayıran başlıca özellikleri, bir ana santrifüj fan ile hızlandırılıp basıncı arttırılmış hava kullanmaları ve ürünü bir siklon ve/veya jet-filtre ile durdurmalarıdır. Sisteme fan ve filtre girdiğinden dolayı da tasarım parametreleri daha karmaşıktır.

\subsection{Dinamik Havalı Ayırıcılarda Tane Boyutu Kontrolü}

Dinamik havalı ayırıcılarda ürün tane boyutu, ayırıcı rotorunun devir hızıyla rotor çevresinde radyal olarak sirküle eden ana fan hava hızının; dolayısıyla fan basıncının bir fonksiyonudur. Ürün tane boyu üst sınırı uygun rotor devir hızı ile fan hava miktarının seçimiyle gerçekleşir. Ürün tane boyutu ayarlanmasında iki ana kural vardır. Bunlar sırasıyla;

1. Kural: Sabit Fan Hava Akım Hızı ve Fan Basıncı için :

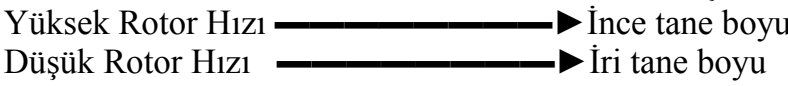

2. Kural: Sabit Rotor Hızı için:

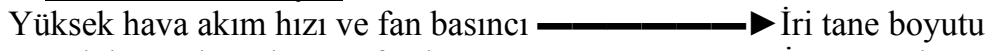

Düşük hava akımı hızı ve fan basıncı $\longrightarrow$ İnce tane boyutu

sonucunu verirler.

Hava akımı ve rotor hızı ile tane boyu üst sınırı arasında aşağıdaki eşitlik kurulabilir:

$$
\mathrm{D}_{\mathrm{t}}=(\mathrm{C} * \mathrm{~V}) / \mathrm{n}^{2}
$$




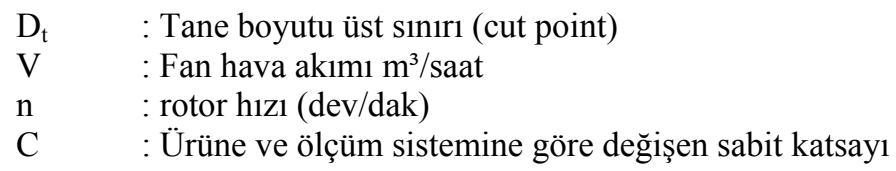

C katsayısını hesaplamak için tane boyutu ve rotor hızı bilinen bir sistemde;

$$
\mathrm{C}=\left(\mathrm{D}_{\mathrm{t}} * \mathrm{n}^{2}\right) / \mathrm{V}
$$

eşitliğinden hesaplanarak formülde yerine konabilir [3].

Uygulamada operatörler, fan hava klapelerini \%75-85 aralığında sabit tutarak tane boyutunu rotor hızıyla ayarlamayı tercih etmektedirler. Ancak bazı özel durumlarda; örneğin dar tane aralığında ürün elde edilmek istendiğinde, klapelerle fan hava akımı arttırılıp sınıflandırıcı hızı yükseltilmektedir. Böylece daha yüksek bir $\mathrm{d}_{50}$ değeri ve daha düşük yüzey alanına sahip bir ürün ortaya çıkmaktadır. Aynı şekilde rotor hızı ve fan basıncı düşürülerek tane boyut dağılım eğrisi yataya yaklaştırılabilir; yani daha düşük bir $\mathrm{d}_{50}$ değeri olan, yüzey alanı daha yüksek daha ince ürün elde edilebilir.

Bütün bu uygulamalar, çalışma esnasında sürekli tane boyutu ölçümleriyle optimize edilir ve dalgalanmalar en aza indirilmeye çalışılır. Günümüz dinamik sınıflandırıcıların en önemli üstünlüklerinden biri de sahip oldukları kontrol parametreleriyle söz konusu dalgalanmaları en aza indirgemiş olmalarıdır. Konuyla ilgili yapılan çalışmalarda fan klapesinin açılıp yüksek hava akımı ve yüksek rotor hızında öğütme veriminin arttığı gözlemlenmiştir [4].

Genel olarak uygulamada fan hava miktarları sabitlenerek ayırıcı rotor devri düşürülüp yükseltilerek istenen tane boyutu elde edilir. Önceleri bu uygulama ayırıcı rotorunun kasnağının değiştirilmesiyle sağlanırken, günümüzde frekans kontrol üniteleriyle ayırıcı rotor hızı üretimde hiçbir durdurma ve kesintiye gitmeden çok hassas bir şekilde ayarlanabilmektedir.

\subsection{Dinamik Ayırıcı Hattı Tasarım Parametreleri}

Bir kuru öğütme hattının tasarlanmasında ve işletilmesinde en önemli kriter, işletme için amaçlanan hedef tane boyuta üretim kapasitesi ile değirmen ve ayırıcının uyumluluğudur. Bu uyum gözetilirken öncelikle değirmenin saatlik çıkış kapasitesi göz önünde bulundurulmalıdır. Değirmen kapasitesi yüksek, fakat ayırıcı kapasitesi düşük tutulduğunda (genelde yapılan hata budur) değirmende bir miktar atıl kapasite ortaya çıkmakta ve genel elektrik verimi bu şekilde büyük ölçüde düşmektedir veya ayırıcı(lar) aşırı yüklenerek verimsiz bir sınıflandırma yapmaya zorlanmaktadır. Sisteme sonradan ayırıcı ilave etmenin de pek çok teknik ve mali zorlukları vardır. Şekil 2'de görülen, tek değirmenli, tek sınıflandırıcılı, hava taşımalı bir öğütme devresi, tasarım ve işletim olarak kolaydır ancak rotor çapı $630 \mathrm{~mm}$ olan bir ayırıcıyla $\mathrm{d}_{97} 25 \mu \mathrm{m}$ boyutunda 3 ton/saat için $\mathrm{d}_{97} 10 \mu \mathrm{m}$ düzeyinin altına inmek mümkün değildir.

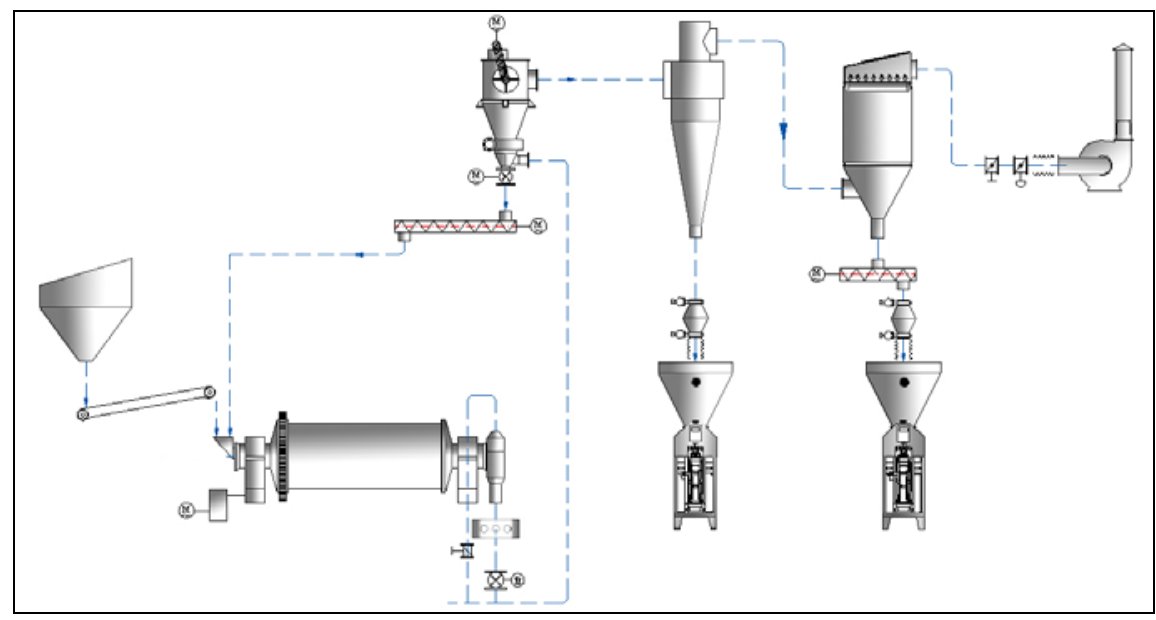

Şekil 2. Yatay yataklı dinamik ayırıcı kullanılan basit öğ̈utme devresi [5] 


\subsubsection{Ayrıcı Rotor Çapı}

Ürünlerin fiyatları ve katma değerleri tane boyutu küçüldükçe arttığından her işletmecinin birincil amacı en ince tane boyutundan en yüksek kapasitede üretim elde etmektir. Ancak ayırıcının rotor çapı bunu sınırlayan önemli bir parametredir. Rotor çapı, dolayısıyla kapasitesi büyüdükçe ayırım yapabileceği tane boyut aralığ yükselir._Rotor çapı ve ayırıcı kapasitesi ile sınıflandırılabilecek tane boyut aralığı ters orantılıdır. Örneğin 750 $\mathrm{mm}$ rotor çapına sahip bir ayırıcı, kalsit ögütmede en düşük $\mathrm{d}_{97} 12 \mu \mathrm{m}$ düzeyine inebilmekte ve kapasitesi de $1500 \mathrm{~kg} / \mathrm{saat}$ 'e gerilemektedir. Rotor çap1 630 mm'ye düştügünde ürün tane boyutu $10 \mu \mathrm{m}$, kapasitesi ise 1200 $\mathrm{kg} /$ saat olarak gerçekleşmektedir [2]. Bu ekipmanlar $\mathrm{d}_{97} 6 \mu \mathrm{m}$ düzeyine ise hiç yaklaşamamaktadır. $\mathrm{D}_{97} 6 \mu \mathrm{m}$ eldesi için rotor çapının 315 mm'ye düşmesi gerekmektedir. Bu defa da kapasite d $\mathrm{d}_{97} 10 \mu \mathrm{m}$ için $350 \mathrm{~kg} / \mathrm{saat}$ 'e kadar düşmektedir. Bir başka deyişle aynı değirmen önüne $750 \mathrm{~mm}$ rotor çaplı tek ayırıcı yeterli gelirken hedef tane boyu $\mathrm{d}_{97} 6 \mu \mathrm{m}$ olduğunda bu sayı 6'ya çıkmaktadır. Bu da 6 adet ayırıcı, 6 adet fan ve filtre; hepsine yetecek kadar da basınçlı hava demektir ki işletme genel verimliliği oldukça düşük gerçekleşecektir (Tablo 1).

Tablo 1. Ayırıcı rotor çapı-adedi ile tane boyu aralıkları, kapasitesi ve gerekli hava miktarı arasındaki ilişki

\begin{tabular}{|lccccccccc|}
\hline Rotor çapı/adedi & $200 / 1$ & $200 / 4$ & $315 / 1$ & $315 / 3$ & $315 / 6$ & $500 / 1$ & $500 / 4$ & $630 / 1$ & $750 / 1$ \\
\hline Tane boyutu aralığ1 & $5-120$ & $5-120$ & $6-150$ & $6-150$ & $6-150$ & $8-150$ & $8-150$ & $9-200$ & $10-200$ \\
\hline Kapasite (kg/saat) : & & & & & & & & & \\
\hline $\mathrm{d}_{97} 6 \mu \mathrm{m}$ & 120 & 480 & 300 & 900 & 1800 & - & - & - & - \\
\hline $\mathrm{d}_{97} 10 \mu \mathrm{m}$ & 180 & 720 & 500 & 1500 & 3000 & 1150 & 4600 & 1800 & 2500 \\
\hline $\mathrm{d}_{97} 20 \mu \mathrm{m}$ & 280 & 1120 & 700 & 2100 & 4200 & 1750 & 7000 & 2800 & 3900 \\
\hline Fan kapasitesi (m/saat) 1000 & 4000 & 2500 & 7500 & 15000 & 7500 & 30000 & 10000 & 14000 \\
\hline
\end{tabular}

NOT: 1-Tablodaki değerler $\mathrm{d}=2,7 \mathrm{gr} / \mathrm{cm}^{3}$ olan $\mathrm{CaCO}_{3}$ ince öğ̈̈tme uygulamaları içindir.

2- Değirmen çıkış malzemesi içinde yaklaşık \% $70 \mathrm{~d}_{97}$ değeri olan ince ürün bulunduğu varsayılmıştır.

$\mathrm{Bu}$ ikilemi üreticiler, 6 adet ayırıcı rotorunu tek bir hazne üzerine yerleştirerek aşmışlardır. Böylelikle kısaca $315 / 6$ olarak adlandıracağımız çok rotorlu yatay yataklı ayırıcılar ortaya çıkmış, yüksek tane boylarında yüksek kapasiteler elde edilirken $d_{97} 6 \mu \mathrm{m}$ gibi aşılamayacak bir sınır da aynı ayırıcı tarafından aşılarak konvansiyonel bilyalı değirmenler tarafından üretilmeye başlanmıştır (Şekil 3).

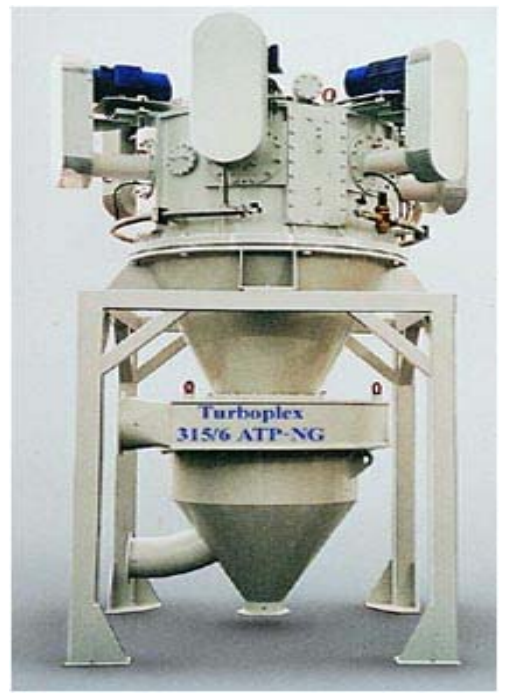

Şekil 3. Altı rotorlu yatay yataklı dinamik ayırıcı ALPINE Turboplex 315/6 [6] 


\subsubsection{Ayırıcı Hattı Tasarımı}

Cevher hazırlama tesislerinde, separatör hatları, siklonlu, siklonsuz; açık devre ya da kapalı devre olarak düzenlenmektedir. Aşağıda siklonlu ve siklonsuz açık devre ayırıcı hatları üzerinde durulacaktır.

\subsubsection{Siklonlu Ayırıcı Hattı}

Ana fanın ayırıcıdan yüksek hızda çektiği ince ürünü durdurmak ve stoklamak için siklon ve jet-filtrenin birlikte kullanıldığı sistemlerdir (Şekil 4). Nispeten kaba ürün eldesi için daha uygundurlar, çünkü siklonlar belli tane boyutlarının altında ürünü durduramamaktadır. Siklonun durduramadığı ince ürün filtre tarafından yakalanıp çöktürülür. Bundan dolayı bu tür sistemlerde siklondan elde edilen malzeme nispeten daha kaba; filtreden elde edilen malzeme nispeten daha incedir. Özellikle bu tip bir ürün istenmiyorsa her iki ürün tek siloya beslenerek karıştırılır.

Siklonlu hatların en önemli avantajı, daha küçük bir jet filtreye ihtiyaç duymalarıdır. Bu şekilde ilk yatırım maliyeti düşeceği gibi filtrenin harcayacağı basınçlı hava miktarı da oldukça azalmaktadır. Önemli dezavantajı ise siklonun ortaya çıkardığı ek basınç kaybının ayırıcı verimini düşürmesidir.

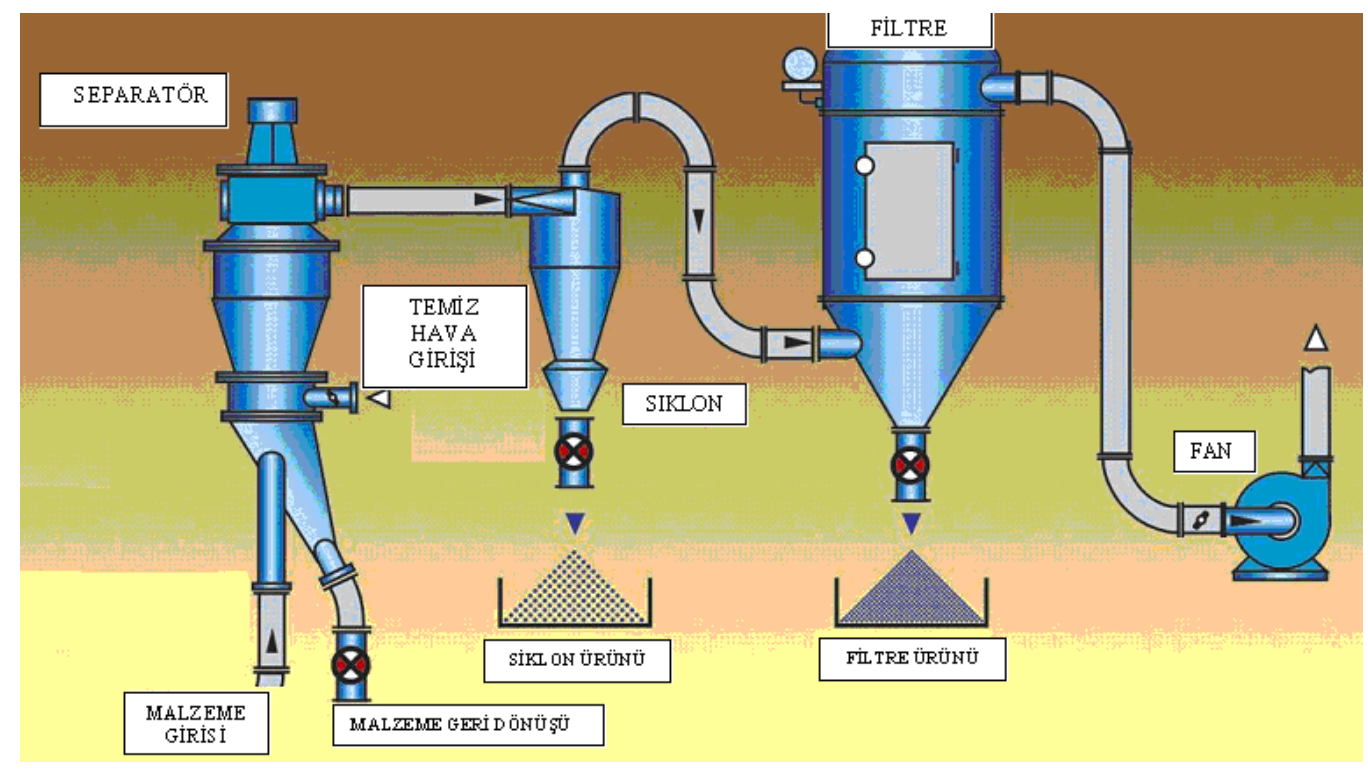

Şekil 4. Siklonlu açık devre ayırıcı hattı [2]

\subsubsection{Siklonsuz Ayırıcı Hattı}

Ayırıcıdan fan tarafından emilen ürünün tek başına jet filtre tarafından durdurulduğu sistemlerdir (Şekil 5). Ana fan basınç kaybı sadece jet filtrede oluşur ve siklonlu hatta göre daha azdır. Bundan dolayı dar tane fraksiyonunda mikronize öğütme prosesleri için daha uygundur. Ayrıca filtre haznesinde biriken ürün üniform bir yapıya sahiptir. En önemli dezavantajı ise büyük ve yüksek basınca dayanıklı filtre gereksinimidir. Bu da filtrenin temizleme devresinin harcayacağı basınçlı hava miktarının yüksek olması, dolayısıyla tesiste daha büyük bir kompresöre ihtiyaç duyulacağından ilk yatırım ve işletme maliyetinin artmasına neden olmaktadır. Ancak bu dezavantaj, elde edilecek dar tane fraksiyonunun getireceği efektif ögütme ile karşılanabilmektedir. Tesis tasarımında bu iki kriter birlikte ele alınıp değerlendirilmelidir. 


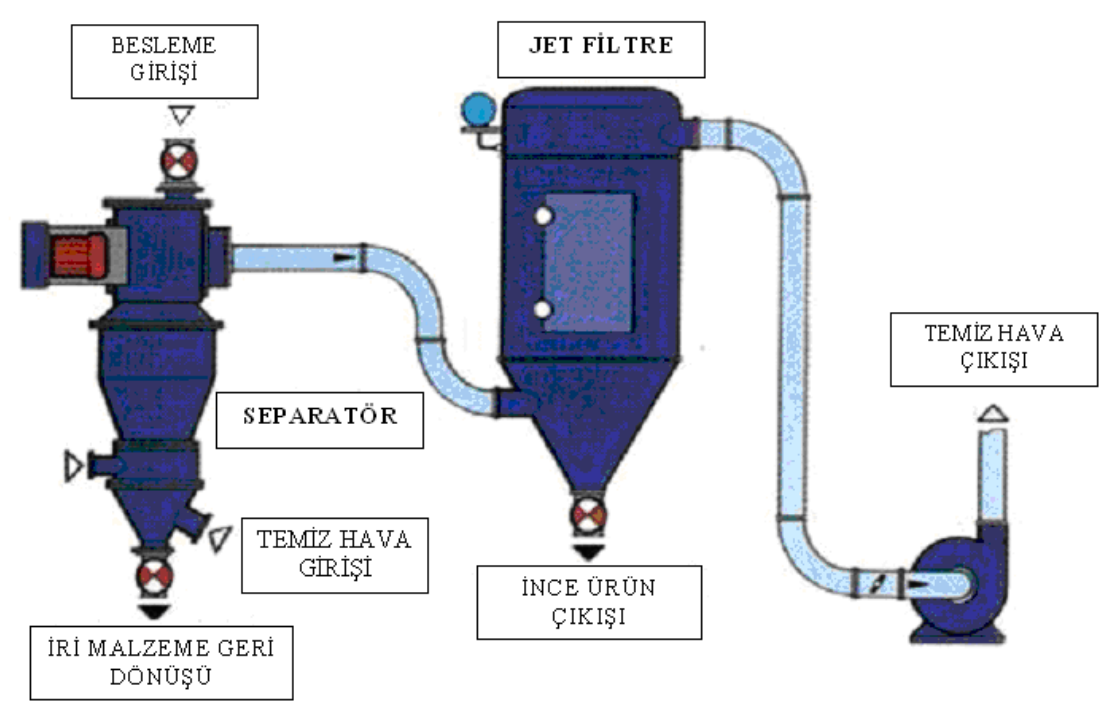

Şekil 5. Siklonsuz açık devre bir ayırıcı-filtre-fan [2]

\section{SONUÇLAR}

Günümüz şartlarında mikronize kuru öğütme tesislerinde ayırıcı tasarım parametrelerinin gerek ilk kuruluş gerek işletme aşamasında bilinmesi, ampirik yaklaşımların ortaya çıkardığı/çıkaracağı muhtemel kayıpların en aza indirgenmesi bakımından önemlidir. Yukarıda kısaca irdelemeye çalıștı̆ııız başlıklar, tesis tasarım ve işletilmesinde analitik bir yaklaşım sağlayacaktır. Hedeflenen tane boyu aralığı ve kapasitesi ile seçilecek ayırıcı özelliklerinin uyumlu olması etkin bir öğütme sağlayacaktır.

\section{KAYNAKLAR}

[1] Shapiro, M. and Galperin, V. (2005) Air classification of solid particles: a review. Chemical Engineering and Processing, Vol. 44, pp.279-285.

[2] Anon. a. (2010) Classifiers, http://www.bikudo.com/airclassifier

[3] Altun, O. ve Benzer, H. (2010) Decreasing specific energy consumption of a cement plant by adjusting the seperator parameters. IMPS'10, pp.99-108.

[4] Anon. b. (1999) Circoplex Classifier Mill Operating Manual BA 1235/5 E Hosokawa-Alpine, 1999, p.31-32.

[5] Anon. c. (2010) Classifiers, http://www.varlikmakina.com/kompletesisler

[6] Anon. d. (1996) Alpine Handbook of Mechanical Processing Technology. 1996. 